\title{
Osteoporosis in men
}

\author{
Waldemar Misiorowski \\ Department of Endocrinology, Centre of Postgraduate Medical Education, Bielański Hospital, Warsaw, Poland
}

\begin{abstract}
Osteoporotic fractures are the leading cause of morbidity and mortality among aging men. $30 \%$ of all hip fractures occur in men, and mortality resulting from not only the hip fracture, but also the spine and other major osteoporotic fractures, is significantly higher in men than in women. As in women, hypogonadism is the best documented risk factor for developing osteoporosis in men. In older men, testosterone levels are negatively correlated with the risk of fractures, and it seems that this age-related testosterone deficiency should not be considered as one of the many causes of secondary osteoporosis, rather one of the major and most important mechanisms of senile osteoporosis. Acute hypogonadism induced by ablation treatment for prostate cancer (surgical or pharmacological castration, antiandrogen therapy) is associated with an extremely high risk of fracture. Other documented causes of bone loss in men are cigarette smoking and alcohol abuse, and a number of diseases that require corticosteroid treatment. Pharmacotherapy of osteoporosis should be recommended to all men with a diagnosed osteoporotic fracture and all men with a high 10-year absolute fracture risk (FRAX ${ }^{\top M}$ ). Not all drugs registered for the treatment of postmenopausal osteoporosis have been registered for the treatment of osteoporosis in men, and others have not been the subject of long-term and costly clinical trials required for such registration. The risk reduction of new fractures was documented only for treatment with zoledronic acid. Risedronate, strontium ranelate, teriparatide, and denosumab in men increase in bone mineral density comparable to that seen in postmenopausal women.
\end{abstract}

Key words: male osteoporosis, hypogonadism, fracture risk, treatment.

\section{Introduction}

While most studies of osteoporosis have focused on postmenopausal women, older men are also at increased risk of fragility fractures [1-4]. The incidence of osteoporotic fractures in men and in women is increasing rapidly, which is related to the fact that both women and men live longer and longer $[5,6]$. Hence, the number of aging men, predisposed to such fractures, is increasing worldwide. At the same time, the lack of widespread awareness of the risk of osteoporotic fractures in men is currently comparable to that of osteoporosis in women 30 years ago. Osteoporotic fractures are the leading cause of morbidity and mortality among aging men $[7,8]$. The risk of at least one typical osteoporotic fracture in a 50-year-old male is estimated to be about 13\% (in women about $40 \%$ ) and for an 80 -yearold man this figure increases to $25 \%$ [9-11]. The risk of vertebral fragility fracture in men is only half as much as in women, and cross-sectional radiological findings suggest that up to one third of men over 65 years old have suffered a fracture [12]. The risk of fracture of the proximal femur (hip) in aging men is $5-6 \%$, compared to $16-18 \%$ in women. This means that $30 \%$ of all hip frac- tures occur in men [13-15]. At the same time, from unexplained causes, mortality in the hip [16-18] as well as in the spine [19] and other major osteoporotic fractures, is significantly higher in men than in women.

The basic factors determining the current bone mass are: the peak bone mass achieved after the age of 20 years and the rate of its loss. During adolescence, bone mass increases rapidly in response to increased secretion of sex hormones. The total increase in bone mineral density (BMD) observed in men, however, only partially reflects the actual increase in the bone mass. It seems that in a greater proportion of women it depends also on the increase in bone size [20,21]. Peak bone mass is achieved in about the twentieth (spine) to the thirtieth (peripheral bones) years of life [22-25]. Bone loss, beginning in most men after 40 years of age, is in fact comparable to the loss of bone mass in women, but in men it is better compensated for by depositing some of the newly formed bone on the outer surface of the bone (periosteal apposition). This increases bone size, and so maintains the strength of the wider bone as well as offsetting bone loss from the inside of the bone. 


\section{Aetiology}

The causes of osteoporosis in men are similar to those of women: hypogonadism, glucocorticoid therapy, gastrointestinal diseases, vitamin D deficiency, anticonvulsant therapy, and alcohol abuse are the most common aetiological factors [26-30].

As in women, hypogonadism is the best documented risk factor for developing osteoporosis in men. In boys with androgen resistance, despite high growth, peak bone mass is not achieved [31, 32]. Also, in Klinefelter syndrome, low bone mass is observed. Androgens play an extremely important role in bone tissue homeostasis. They directly stimulate the proliferation, differentiation, and function of osteoblasts, inhibit osteoclast recruitment, and influence interactions between osteoclasts and osteoblasts. They stimulate growth hormone secretion $(\mathrm{GH})$, increase the sensitivity of bone cells to IGF-1, and stimulate the production of bone matrix [21]. Androgen receptors have been localised in both osteoblasts and osteoclasts [33]. However, it appears that also oestrogens play a significant role in the aetiopathogenesis of osteoporosis in men, as in women [33-35]. There is a positive correlation between serum oestradiol concentrations and bone mineral density of men [23]. Severe osteoporosis has been reported in men with deletion of oestrogen receptor gene, and aromatase-deficient males. It worth stressing, however, that a risk of fracture in men correlates with oestradiol concentration only in the range of extremely low (post-castration) values: less than $16-20 \mathrm{pg} / \mathrm{ml}$ [36]. It appears therefore, that there is a threshold value for oestradiol concentration in men, necessary for the proper functioning of bone metabolism, above which oestradiol no longer plays a key role in protecting men from osteoporosis.

In elderly men, testosterone levels are inversely correlated with fracture risk [37], which may reflect not only the direct anabolic effects of androgens on bone mass, but also the periosteal apposition and bone size increase, favouring biomechanics of fractures. Androgens also act indirectly by affecting non-skeletal factors such as muscle mass and strength, balance, and risk of falls. Taking into account that about $70 \%$ of men with osteoporosis also experience other symptoms of testosterone deficiency syndrome (TDS), it seems that agerelated testosterone deficiency should not be considered as a one of the many causes of secondary osteoporosis, but rather as one of the major and most important mechanisms of involutive (senile) osteoporosis [38, 39]. It also should be stressed that, in contrast to the rapid decrease in oestrogen levels in postmenopausal women, the decrease of testosterone secretion in aging men is much more extended in time. Consequently, men do not experience rapid acceleration of bone loss. As a consequence, the exponential increase in frequency of osteoporotic fractures with age is approximately five to seven years delayed in men, compared to women.

Androgen deficiency in younger males may result mainly from castration or hyperprolactinaemia, with particular attention to the increasing group of men with acute hypogonadism induced by androgen-deprivation therapy for prostate cancer (surgical or pharmacological castration, antiandrogen therapy) and at the highest risk for fractures [45].

Documented causes of bone loss in men are cigarette smoking and alcohol abuse [26, 30]. Also, a number of diseases that require treatment with corticosteroids, such as rheumatoid arthritis or asthma, can result in secondary osteoporosis and bone fractures, as in women.

\section{Diagnosis}

Due to the painless early period of osteoporosis, there is no symptom of its development until a fracture occurs. Thus, of utmost importance in diagnosing osteoporosis is the possibility of early detection of the risk of this disease. Unfortunately, often the only time a patient realises he has a problem is when he breaks a bone - and even then, the diagnosis of osteoporosis is frequently overlooked. DXA densitometry should be recommended for all men over the age of 70 years, who have experienced clinical risk factors for fracture or a significant ( $2 \mathrm{~cm}$ or more) reduction in growth.

Comprehensive assessment of fracture risk over a ten-year period (FRAX ${ }^{T M}$ ) integrates selected clinical risk factors (age, sex, previous fragility fracture after 45 years, corticosteroid therapy, smoking and alcohol abuse, rheumatoid arthritis, and other secondary causes of bone loss) and diagnostic findings (DXA densitometry). A fracture probability of more than $10 \%$ is indicative of pharmacotherapy [46]. In the case of a moderate fracture probability (5-10\%), additional factors increasing actual fracture risk, such as corticosteroid dose and risk of falls, should be taken into account. In particular, imaging of thoracic and lumbar spine (X-ray, VFA) to exclude or to confirm the presence of "silent" vertebral fractures should always be considered. In men, up to $80 \%$ of fragility vertebral fractures are made without a clear clinical manifestation. At the same time, previous osteoporotic fracture is the most important risk factor for subsequent fractures, multiplying it by several or even several times. Therefore, according to current recommendations, an osteoporotic fracture of the spine or the hip is an absolute indication for the implementation of the treatment - both by the primary care physician and by a specialist, regardless of the stage of the disease and the occurrence of other fracture risk factors [46].

Due to the fact that osteoporosis reflects rather quantitative but not qualitative, the results of traditional biochemical research in patients with uncomplicated osteoporosis remain generally normal. They are, however, 
crucial for excluding the secondary causes of bone loss or pathological fractures. Basic laboratory tests for differential diagnosis of osteoporosis include OB and blood morphology, $\mathrm{Ca}$, creatinine and total protein levels, serum alkaline phosphatase, and vitamin D (serum 25OHD). At further stages of the diagnostic procedure, the daily urinary calcium excretion and serum PTH (hyperparathyroidism), TSH (hyperthyroidism), and PSA (prostate cancer) or other tumour markers and monoclonal proteins or bone marrow biopsy are used.

\section{Treatment: Fewer medicines registered for the treatment of osteoporosis in men}

The aim of the treatment in osteoporosis is to prevent all-life fractures in those who have not yet suffered, and to reduce the risk of fractures in patients with advanced osteoporosis. Comprehensive fracture prevention should address all men over the age of 65 years and should be aware of the risks, modifications of lifestyle, and nutrition, and, as far as possible, the elimination of risk factors for fracture, and prevention of falls.

Pharmacotherapy of osteoporosis should be recommended to all men diagnosed with osteoporotic fracture and to all men with a high 10-year absolute fracture risk (FRAX) [46]. However, there is much less research on the treatment of osteoporosis in men compared to women. Not all drugs registered for the treatment of postmenopausal osteoporosis have been registered for the treatment of osteoporosis in men, and others have not been the subject of long-term and costly clinical trials required for such registration.

Supplementation of calcium and vitamin D is the basis of both prophylaxis as well as the pharmacotherapy in the prevention of osteoporotic fractures. It should be emphasised that, in addition to the direct effect on bone metabolism, vitamin D has a strong, beneficial effect on muscle strength and function, and thus reduces the risk of falling [47].

There have been few trials of osteoporosis therapies performed specifically in male populations, the available trials are relatively small, and in most the endpoint has been a change in BMD, compared to the results obtained in appropriate postmenopausal osteoporosis studies. Only one (zoledronic acid) was originally designed to assess the impact on fracture risk as a primary end point. None of the studies predicted prolonged follow-up or follow-up as an open study.

Testosterone increases bone mineral density in men with low levels of this hormone. However, this effect is limited to patients with baseline serum testosterone levels below $2.0 \mathrm{ng} / \mathrm{ml}(7.5 \mathrm{nmol} / \mathrm{l})$ [48]. The impact of such treatment on the risk of fractures has not been documented. In 241 men treated for two years with alendronate $10 \mathrm{mg} / \mathrm{d}$ vs. placebo, a significant increase in BMD was shown. Significant reductions in the number of mor- phometric vertebral fractures have also been reported in comparison with placebo $(\mathrm{OR}=0.10 ; 95 \% \mathrm{Cl}$ : 0.00-0.88) [49]. Risedronate in 284 men effectively increased bone mineral density in comparison with placebo, but no significant effect on the risk of fractures was found [50]. In a randomised, placebo-controlled study of 1199 men with osteoporosis, treatment with zoledronic acid resulted in a significant reduction in the risk of new vertebral fractures, by $67 \%$ (RR: 0.33; 95\% Cl: 0.16-0.70) [51]. Strontium ranelate also significantly increases bone mineral density in men with osteoporosis, to a similar extent as in women, but the study did not have sufficient statistical power to demonstrate significant reductions in fracture risk [52]. Teriparatide (1-34 rhPTH) has been registered for the treatment of "severe" osteoporosis in men: after numerous fragility fractures, with multiple risk factors or ineffective prior therapy [53]. In men treated with denosumab for two years, there was a significant increase in BMD in lumbar vertebrae, total hip, femoral neck, trochanter, and $1 / 3$ radius, respectively, by $8.0 \%, 3.4 \%, 3.4 \%$, and $4.6 \%$ ( $p<0.01$ for all values). In men who received a placebo in the first year of the study, the change to denosumab in the second year of follow-up resulted in an increase in BMD similar to the one obtained by men from the beginning of treatment with denosumab. The amount of bone mineral density obtained is comparable to that seen in postmenopausal women and men receiving androgen-deprivation therapy for prostate cancer [54].

\section{Disclosure}

Author reports no conflict of interest.

\section{References}

1. Kanis JA, Johnell O, Oden A, et al. Long-term risk of osteoporotic fracture in Malmö. Osteoporosis Int 2000; 11: 669-674.

2. Kanis JA, Johnell O, Oden A, et al. Epidemiology of osteoporosis and fracture in men. Calcified Tissue Int 2004; 75: 90-99.

3. Haentjens P, Johnell O, Kanis JA, at al. On behalf of the Network on Male Osteoporosis in Europe (NEMO). Evidence from data searches and life-table analyses for gender-related differences in absolute risk of hip fracture after Colles' or spine fracture: Colles' fracture as an early and sensitive marker of skeletal fragility in Caucasian men. J Bone Miner Res 2004; 19: 1933-1944.

4. Kanis JA, Pitt FA. Epidemiology of osteoporosis. Bone 1992; 13: S7-15.

5. Cooper C, Campion G, Melton LJ. Hip fractures in the elderly: A worldwide projection. Osteoporosis Int 1992; 2: 285-289.

6. Van der Klift M, De Laet CE, McCloskey EV, et al. The incidence of vertebral fractures in men and women: The Rotterdam Study. J Bone Miner Res 2002; 17: 1051-1056.

7. Center JR, Nguyen TV, Schneider D, et al. Mortality after all major types of osteoporotic fracture in men and women: an observational study. Lancet 1999; 353: 878-882.

8. Poor G, Atkinson EJ, O'Fallon WM, Melton LJ 3rd. Determinants of reduced survival following hip fractures in men. Clin Orthop Related Res 1995; 319: $260-265$

9. Nguyen TV, Eisman JA, Kelly PJ, et al. Risk factors for osteoporotic frac tures in elderly men. Am J Epidemiol 1996; 144: 255-263.

10. Seeman E. The dilemma of osteoporosis in men. Am J Med 1995; 98 : $76 \mathrm{~S}-88 \mathrm{~S}$. 
11. Melton LJ, Atkinson EJ, O'Conner MK, et al. Bone density and fracture risk in men. J Bone Miner Res 1998; 13: 1915-1923.

12. Gehlbach SH, Bigelow C, Heimisdottir M, et al. Recognition of vertebral fracture in a clinical setting. Osteoporos Int 2000; 11: 577-582.

13. De Laet $\mathrm{CE}$, van Hout $\mathrm{BA}$, Burger $\mathrm{H}$, et al. Bone density and risk of hip fracture in men and women: cross sectional analysis. BMJ 1997; 315: 221-225.

14. Schuit SC, van der Klift M, Weel AE, et al. Fracture incidence and as sociation with bone mineral density in elderly men and women: the Rotterdam Study. Bone 2004; 34: 195-202.

15. Melton LJ 3rd, Chrischilles EA, Cooper C, et al. Perspective. How many women have osteoporosis? J Bone Miner Res 1992; 7: 1005-1010.

16. Diamond TH, Thornley SW, Sekel R, Smerdely P. Hip fracture in elderly men: prognostic factors and outcomes. Med J Aust 1997; 167: 412-418.

17. Melton L, Riggs B. Epidemiology of age-related fractures. In: Avioli L (ed.) The Osteoporotic Syndrome. Grune \& Stratton, New York 1983; 45-72.

18. Kiebzak GM, Beinart GA, Perser K, et al. Undertreatment of osteoporosis in men with hip fracture. Arch Intern Med 2002; 162: 2217-2222.

19. Center JR, NguyenTV, Schneider D, et al. Mortality after all major types of osteoporotic fracture in men and women: an observational study. Lancet 1999; 353: 878-882.

20. Krabbe S, Christiansen C. Longitudinal study of calcium metabolism in male puberty. I. Bone mineral content, and serum levels of alkaline phosphatase, phosphate and calcium. Acta Paediatr Scand 1984; 73: 745-749.

21. Krabbe S, Hummer L, Christiansen C. Longitudinal study of calcium metabolism in male puberty. II. Relationship between mineralization and serum testosterone. Acta Paediatr Scand 1984; 73: 750-755.

22. Gilsanz V, Gibbens DT, Roe TF, et al. Vertebral bone density in children: effect of puberty. Radiology 1988; 166: 847-850.

23. Bonjour JP, Theintz G, Buchs B, et al. Critical years and stages of puberty for spinal and femoral bone mass accumulation during adolescence. J Clin Endocrinol Metab 1991; 73: 555-563.

24. Theintz G, Buchs B, Rizzoli R, et al. Longitudinal monitoring of bone mass accumulation in healthy adolescents: evidence for a marked reduction after 16 years of age at the levels of lumbar spine and femora neck in female subjects. J Clin Endocrinol Metab 1992; 75: 1060-1065.

25. Mazess RB, Cameron JR. Bone mineral content in normal U.S. whites. In: Mazess RB (ed.). Proceedings, International Conference on Bone Mineral Measurement. DHEW Publication NIH 75-683, Washington, D.C. 1974; 228-238.

26. Seeman E, Melton LJ 3rd, O'Fallon WM, Riggs BL. Risk factors for spinal osteoporosis in men. Am J Med 1983; 75: 977-983.

27. Kelepouris N, Harper KD, Gannon F, et al. Severe osteoporosis in men. Ann Intern Med 1995; 123: 452-460.

28. Diamond T, Smerdely P, Kormas N, et al. Hip fracture in elderly men the importance of subclinical vitamin D deficiency and hypogonadism. Med J Aust 1998; 169: 138-141.

29. Misiorowski W, Rabijewski M, Zgliczyński W. Osteoporosis in aging males after hip fracture. J Bone Miner Res 2011; 26: 253.

30. Dalen N, Lamke B. Bone mineral losses in alcoholics. Acta Orthop Scand 1976; 47: 469-471.

31. Guo CY, Jones TH, Eastell R. Treatment of isolated hypogonadotropic hypogonadism effect on bone mineral density and bone turnover. J Clin Endocrinol Metab 1997; 82: 658-665.

32. Sobel V, Schwartz B, Zhu YS, et al. Bone mineral density in the complete androgen insensitivity and 5alpha-reductase-2 deficiency syndromes. J Clin Endocrinol Metab 2006; 91: 3017-3023.

33. Falahati-Nini A, Riggs BL, Atkinson EJ, et al. Relative contributions of testosterone and estrogen in regulating bone resorption and formation in normal elderly men. J Clin Invest 2000; 106: 1553-1560.

34. Leder BZ, LeBlanc KM, Schoenfeld DA, et al. Differential effects of androgens and estrogens on bone turnover in normal men. J Clin Endocrino Metab 2003; 88: 204-210.

35. Amin S, Zhang Y, Felson DT, et al. Estradiol, testosterone, and the risk for hip fractures in elderly men from the Framingham Study. Am J Med 2006; 119: 426-433.

36. Mellström D, Vandenput L, Mallmin $\mathrm{H}$, et al. Older men with low serum estradiol and high serum SHBG have an increased risk of fractures. J Bone Miner Res 2008; 23: 1552-1560

37. Meier C, Nguyen TV, Handelsman DJ, et al. Endogenous sex hormones and incident fracture risk in older men: the Dubbo Osteoporosis Epidemiology Study. Arch Intern Med 2008; 168: 47-54.
38. Riggs BL, Kholsa S, Melton LJ 3rd. A unitary model for involutional osteoporosis: estrogen deficiency causes both type 1 and type 2 osteoporosis in postmenopausal women and contributes to bone loss in aging men. J Bon Miner Res 1998; 13: 763-773.

39. Khosla S, Melton LJ 3rd, Atkinson EJ, et al. Relationship of serum sex steroid levels to longitudinal changes in bone density in young versus elderly men. J Clin Endocrinol Metab 2001; 86: 3555-3561.

40. Stepan JJ, Lachman M, Zverina J, et al. Castrated men exhibit bone loss: effect of calcitonin treatment on biochemical indices of bone remodeling. J Clin Endocrinol Metab 1989; 69: 523-527.

41. Chen Z, Maricic M, Nguyen P, et al. Low bone density and high percentage of body fat among men who were treated with androgen deprivation therapy for prostate carcinoma. Cancer 2002; 95: 2136-2144.

42. Maillefert JF, Sibilia J, Michel F, et al. Bone mineral density in men treated with synthetic gonadotropin-releasing hormone agonists for prostatic carcinoma. J Urol 1999; 161: 1219-1222.

43. Mittan D, Lee S, Miller E, et al. Bone loss following hypogonadism in men with prostate cancer treated with GnRH analogs. J Clin Endocrinol Metab 2002; 87: 3656-3661.

44. Daniell HW. Osteoporosis after orchiectomy for prostate cancer. J Urol 1997; 157: 439-444.

45. Shahinian VB, Kuo YF, Freeman JL, et al. Risk of fracture after androgen deprivation for prostate cancer. N Engl J Med 2005; 352: 154-164.

46. Lorenc R, Głuszko P, Karczmarewicz E, et al. Zalecenia postępowania diagnostycznego i leczniczego w osteoporozie. Aktualizacja 2013. Medycyna Praktyczna - Wydanie Specjalne Reumatologia 1/2013.

47. Bischoff-Ferrari HA, Dawson-Hughes B, Staehelin HB, et al. Fall prevention with supplemental and active forms of vitamin $D$ : a meta-analysis of randomised controlled trials. BMJ 2009; 339: b3692.

48. Snyder PJ, Peachey H, Hannoush P, et al. Effect of testosterone treatment on bone mineral density in men over 65 years of age. J Clin Endocrinol Metab 1999; 84: 1966-1972.

49. Orwoll E, Ettinger $M$, Weiss $S$, et al. Alendronate for the treatment of osteoporosis in men. N Engl J Med 2000; 343: 604-610.

50. Boonen S, Orwoll ES, Wenderoth D, et al. Once-weekly risedronate in men with osteoporosis: results of a 2-year, placebo-controlled, doubleblind, multicenter study. J Bone Miner Res 2009; 24: 719-725.

51. Boonen S, Reginster JY, Kaufman JM, et al. Fracture risk and zoledronic acid therapy in men with osteoporosis. N Engl J Med 2012; 367: 1714-1723.

52. Kaufman JM, Audran M, Bianchi G, et al. Efficacy and safety of strontium ranelate in the treatment of osteoporosis in men. J Clin Endocrinol Metab 2013; 98: 592-601.

53. Orwoll ES, Scheele WH, Paul S, et al. The effect of teriparatide [human parathyroid hormone (1-34)] therapy on bone mineral density in men with osteoporosis. J Bone Miner Res 2003; 18: 9-17.

54. Langdahl BL, Stubbe Teglbjærg C, Ho PR, et al. A 24-month study evaluating the efficacy and safety of denosumab for the treatment of men with low bone mineral density: results from the ADAMO trial. J Clin Endocrinol Metab 2015; 100: 1335-1342. 